\title{
PEMBANGUNAN SMOKING AREA UNTUK MENINGKATKAN KUALITAS HIDUP MASYARAKAT DI KAWASAN EKS- LOKALISASI DOLLY
}

\author{
Surya Hermawan ${ }^{*}$, Joko Purnomo², Handy Prayogo ${ }^{3}$, Hans Handoyo ${ }^{4}$, \\ Jonathan Setiawan ${ }^{5}$ \\ 1,2 Program Studi Teknik Sipil, Universitas Kristen Petra, Jl Siwalankerto 121-131, Surabaya 60236 \\ Email: 1 shermawan@petra.ac.id, 2jpurnomo@petra.ac.id \\ 3,4.5 Mahasiswa Program Studi Teknik Sipil, Universitas Kristen Petra, Jl Siwalankerto 121-131, Surabaya 60236 \\ Email: ${ }^{3}$ handy@john.petra.ac.id, ${ }^{4}$ hans@john.petra.ac.id, ${ }^{5}$ jonathan@john.petra.ac.id \\ * Penulis korespondensi; Email: shermawan@petra.ac.id
}

\begin{abstract}
Abstrak: Asap rokok mengandung banyak zat berbahaya bagi tubuh manusia, terutama bagi perokok aktif. Namun, berdasarkan penelitian beberapa tahun belakangan ini, dampak yang sama ditimbulkan oleh asap rokok kepada orang yang tidak merokok-perokok pasif (passive smoking). Lebih lanjut, tidak terkendalinya peredaran rokok menyebabkan tren merokok di tempat umum merajalela. Fenomena serupa seperti seseorang merokok di dalam rumah, kantor, tempat umum, bahkan di kendaran umum terlihat jelas di kawasan Eks-Lokalisasi Dolly, Kelurahan Putat Jaya, Kota Surabaya, Jawa Timur. Perilaku tersebut membawa dampak negatif bagi lingkungan, terutama bagi ibu-ibu dan anak-anak sebagai perokok pasif (passive smoker). Untuk mengurangi dampak negatif perilaku passive smoking diperlukan sebuah tindakan nyata untuk menyadarkan masyarakat untuk hidup sehat dan bebas dari asap rokok. Paper ini membahas tentang kegiatan pengabdian kepada masyarakat berbasis service learning dengan hasil nyata berupa pembangunan smoking area. Kegiatan pengabdian kepada masyarakat ini melibatkan 120 Mahasiswa Program Studi Teknik Sipil Universitas Kristen Petra. Proses pengabdian kepada masyarakat ini dilaksanakan dalam tiga tahap, meliputi prapelaksanaan, pelaksanaan pembangunan smoking area, dan paska pelaksanaan. Berdasarkan hasil akhir yang dicapai, program ini dinilai berhasil meningkatkan kesadaran masyarakat untuk hidup sehat dan bebas dari asap rokok, serta menjadikan smoking area sebagai tempat berkumpul dan berdiskusi untuk melakukan hal-hal positif.
\end{abstract}

Kata kunci: Eks-lokalisasi Dolly; perokok pasif; rokok; service learning; smoking area

\begin{abstract}
Cigarette smoke contains harmful substances to human bodies, particularly to smokers. However, according to recent researches, equal impact sustained by inactively smoking individual, namely passive smoker (passive smoking). Furthermore, uncontrolled distribution of cigarettes causes smoking activity in public places become common. Similar phenomenon, such as people smoke in the houses, offices, public areas, and even in public transportation are very obvious in Ex-Dolly Localization, in Putat Jaya District, Surabaya, East Java. Such phenomenon brings negative impact to surrounding environment, mostly to women and children as a passive smoker. In order to reduce this negative effects of passive smoking, a real action is needed to evoke the society to have a healthy and smoke-free life. This paper disseminates the noble act of service learning-based community service with a real outcome by building a smoking area for the community. The program involved 120 Students of Civil Engineering Department, Petra Christian University. The program was done in three phases, i.e. pre-action, main action, and post-action. Based on the final result, the program was considered successful in evoking community consciousness to live a healthy smoke-free life, as well as making the smoking area as a place to assemble and further discuss positive activities.
\end{abstract}

Keywords: Cigarette; Ex-Dolly localization; passive smoking; service learning; smoking area.

\section{PENDAHULUAN}

Beberapa tahun belakangan ini Indonesia menghadapi berbagai masalah kesehatan, di mana salah satunya adalah timbulnya berbagai penyakit kronis akibat asap rokok. Penyakit yang merupakan akibat asap rokok seperti kanker, serangan jantung, impotensi, gangguan saluran pernapasan, dan gangguan kehamilan banyak ditemui pada perokok aktif, yaitu mereka yang secara aktif 
menghisap rokok. Namun, menurut penelitianpenelitian yang dilakukan beberapa tahun terakhir, didapati bahwa risiko yang sama juga dimiliki oleh mereka yang secara tidak sengaja menghirup asap rokok ketika berada di lingkungan yang terpapar asap rokok, atau lebih dikenal dengan istilah perokok pasif (Cancer Research, 2016; Eisner et al., 1998).

Perokok pasif mempunyai risiko yang sama tinggi dengan perokok aktif dalam terjangkit penyakit kronis akibat paparan asap rokok. Berdasarkan data Global Youth Survey tahun 1999-2006, sebanyak $81 \%$ remaja usia $13-15$ tahun di Indonesia menjadi perokok pasif karena terpapar asap rokok di tempat umum. Nilai ini relatif jauh lebih tinggi dibandingkan rata-rata persentase dunia yang hanya sebesar 56\% (Amelia, 2016). Selain itu survei menunjukkan bahwa lebih dari 150 juta penduduk di Indonesia menjadi perokok pasif di rumah, kantor, tempat umum, bahkan kendaraan umum. Sementara itu, data Survei Sosial Ekonomi Nasional 2004 menunjukkan bahwa lebih dari 87\% perokok aktif merokok di dalam rumah ketika sedang bersama anggota keluarga. Menurut hasil kajian World Health Organization (WHO), menciptakan area bebas asap rokok melalui pembuatan smoking area merupakan salah satu strategi paling efektif untuk memberikan perlindungan bagi perokok pasif (Devina, 2017).

Beberapa studi mengindikasikan bahwa orang yang memiliki pengetahuan yang lebih baik cenderung melindungi diri mereka dan sesama dari paparan asap rokok dengan cara membuka jendela, membuat larangan merokok di dalam rumah, dan menjaga anak mereka agar terhindar dari lingkungan perokok (Blackburn et al., 2003; Dunn et al., 2008; Evans et al., 2011). Banyak negara berkembang telah melakukan usaha, termasuk salah satunya membuat smoking area, untuk mengurangi risiko terpaparnya perokok pasif di ruang publik dan di dalam rumah (Britton and Bogdanovica, 2013; Callinan et al., 2010; Fong et al., 2013; Hahn, 2010; Jarvis et al., 2011).

Sementara itu, dampak yang ditimbulkan perilaku perokok pasif dapat dilihat dengan jelas di kawasan Eks-Lokalisasi Dolly, Kelurahan Putat Jaya, yang merupakan lokasi kegiatan Pengabdian kepada Masyarakat (PkM) berbasis Service Learning (SL) ini. Sebagai contoh seorang ayah merokok di dalam rumah menyebabkan istri dan anakanaknya, sebagai perokok pasif, turut merasakan dampak yang diakibatkan oleh asap rokok yang dihasilkan (Cahyani and Rahmawati, 2016). Hal ini menjadi penyebab turunnya kualitas hidup sehat di kawasan tersebut. Terlebih lagi yang menjadi korban adalah ibu-ibu dan anak-anak. Oleh karena itu, sebuah tindakan nyata untuk memutus rantai dampak negatif dari perilaku perokok pasif harus segera dilakukan. Berdasarkan kajian sebelumnya, pembuatan smoking area merupakan salah satu strategi paling efektif yang dapat digunakan (Devina, 2017).

Kegiatan ini merupakan suatu bagian dari suatu pelaksanaan kegiatan service learning yang telah berjalan beberapa semester secara komprehensif. Dan beberapa kegiatan yang bersamaan di semester ini, meliputi: pembuatan toilet, tempat cuci tangan, pembuatan smoking area, lomba gambar, lomba mewarnai serta lomba cuci tangan. Service learning ini juga berkelanjutan dikarenakan telah dilakukan pada lokasi yang sama dan melanjutkan kegiatan sebelumnya pada beberapa waktu yang lalu. Kegiatan ini tetap dilanjutkan dengan pertimbangan beberapa hal yaitu: pihak masyarakat mendapat manfaat langsung dari kegiatan yang telah dilakukan, partisipasi masyarakat dan pihak-pihak terkait sangat tinggi dan antusias, sedangkan pihak UK Petra juga mendapat manfaat, bagi Mahasiswa, mereka dapat berlatih bersosialisasi dengan masyarakat, mempraktekan teori yang telah di dapatkan. Untuk masa depan, mereka memiliki rasa empati, karena ketika mereka telah mencoba melakukan sesuatu yang biasanya seorang Tukang lakukan, mereka akan memiliki pengalaman bahwa tidak mudah menjadi seorang tukang karena membutuhkan skill dan keterampilan untuk memberikan hasil yang baik, dari segi: kekuatan, keakuratan/presisi maupun kualitas. Mahasiswa juga dapat belajar bertanggung jawab sesuai dengan apa yang kelompok mereka kerjakan. Untuk institusi UK Petra juga membuktikan melalui kegiatan service learning ini mencerminkan bahwa sebagai institusi, tidak seperti menara gading yang ekslusif, karena seluruh kegiatan dilakukan secara inklusif bersama sama dengan pihak - pihak yang terkait.

Tujuan dari pengabdian kepada masyarakat berbasis service learning ini adalah untuk mengubah perilaku masyarakat mengenai kesehatan dengan membuat sebuah smoking area di kawasan Eks-Lokalisasi Dolly, RT 03/ RT 04 - RW 05, Kelurahan Putat Jaya, Kota Surabaya, Jawa Timur. Melalui pembuatan smoking area ini, diharapkan (a) para perokok aktif tidak merokok lagi di dalam rumah maupun di tempat umum secara sembarang, (b) menjadi tempat berkumpul dan berdiskusi hal-hal positif, (c) mampu meningkatkan kesadaran masyarakat mengenai bahaya dampak yang ditimbulkan akibat perilaku perokok pasif, dan (d) menjadi tempat belajar yang menyenangkan bagi anak-anak sekolah usai menyelesaikan kegiatan di sekolah.

\section{METODE PELAKSANAAN}

Metode pelaksanaan kegiatan pengabdian kepada masyarakat berbasis service learning dalam 
pembuatan smoking area di kawasan Eks-Lokalisasi Dolly Kelurahan Putat Jaya ini, terbagi dalam tiga kategori, yaitu prapelaksanaan, pelaksanaan, dan paska pelaksanaan. Pada tahap prapelaksanaan, tim pengabdian melakukan survei pendahuluan dan diskusi bersama ketua RT 03 dan RT4 - RW 05, Kelurahan Putat Jaya, untuk mengetahui kebutuhan masyarakat berkaitan dengan smoking area (lihat Gambar 1). Melalui survei pendahuluan tersebut, tim pengabdian kepada masyarakat menentukan lokasi yang tepat untuk pembangunan smoking area. Lebih lanjut, tim pengabdian mempersiapkan desain smoking area yang akan dibangun dengan memperhitungkan aspek tata letak, aksesibilitas, kekuatan, estetika, serta alat dan bahan yang dibutuhkan. Setelah mengidentifikasi permasalahan yang ada secara komprehensif, maka tahap prapelaksanaan dilanjutkan dengan pengurusan surat ijin untuk pelaksanaan kegiatan pengabdian kepada masyarakat. Melalui diskusi dengan perangkat RT, maka jadwal pelaksanaan pengabdian dilaksanakan pada hari Sabtu, tanggal 11 dan 18 November 2017.

Kegiatan service learning (SL) ini diawali dengan kegiatan bersama dengan warga serta pihak pihak yang terlibat. Seperti yang dapat dilihat pada Gambar 2 dan 3, para pihak terkait yang terlibat dalam kegiatan ini menyempatkan diri untuk hadir di awal kegiatan seperti melakukan senam dan ramah tamah maupun sosialisasi mengenai program yang ada. Dengan adanya sinergi yang baik dari berbagai pihak, maka di awal pelaksanaan terasa rasa kebersamaan untuk kemajuan dan kebaikan bersama.

Tahap berikutnya adalah pelaksanaan pembuatan smoking area, yang melibatkan sebanyak kurang lebih 600 orang yang terdiri dari masyarakat setempat, Dosen dan Mahasiswa Prodi Teknik Sipil, Mahasiswa Manajemen Bisnis Universitas Kristen Petra, dan Dinas Instansi terkait lainnya seperti: Dinas Kesehatan Propinsi Jawa Timur, Daerah maupun Putat Jaya, Kelurahan Putat Jaya, Kelompok Kerja (Pokja) Putat Jaya, RW dan RT Kegiatan ini merupakan suatu bagian dari

Pada tahap ini, mahasiswa peserta pengabdian kepada masyarakat berbasis service learning ini dibagi ke dalam beberapa kelompok untuk mengerjakan masing-masing bagian dalam pembuatan smoking area. Diawali dengan pembuatan perencanaan denah lokasi yang disesuai kan dengan kondisi yang ada. Seperti yang dapat dilihat pada Gambar 4. Denah Smoking Area berukuran 3,2 m x $2,8 \mathrm{~m}$. Gambar tersebut juga dilengkapi dengan material yang akan digunakan seperti: kayu usuk dan atap dari seng. Untuk lebih jelasnya kebutuhan alat dan bahan yang digunakan pada pembuatan konstruksi sederhana ini dapat dilihat pada Tabel 1, seperti: gergaji, bor listrik, palu, pisau pahat, gerinda, kayu, papan, atap asbes, kalsiplank, kalsiboard, paku, semen dan pasir.

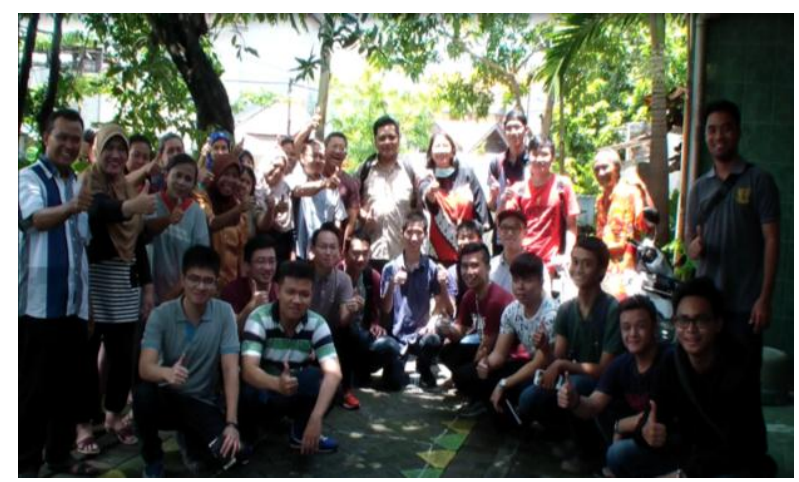

Gambar 1. Kegiatan Survei di Awal Kegiatan

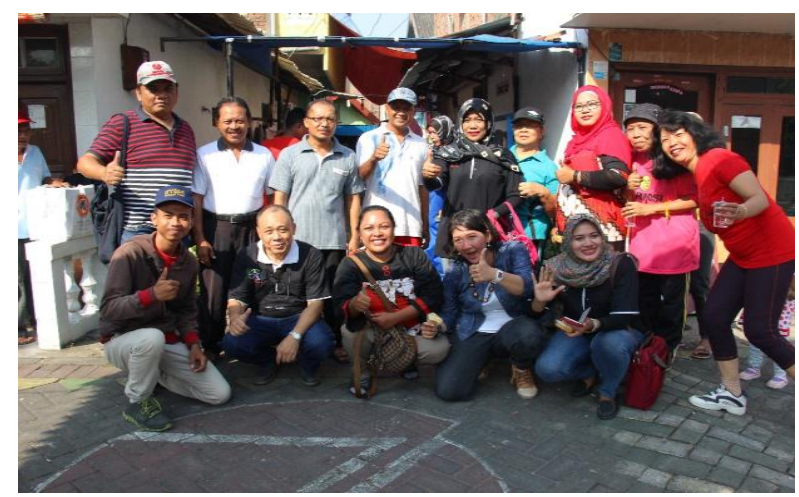

Gambar 2. Kegiatan Awal Bersama Pihak Terkait: Dinas Kesehatan Propinsi, Daerah, UNDP, Puskesmas, RW, RT, Kelompok Kerja dan Masyarakat

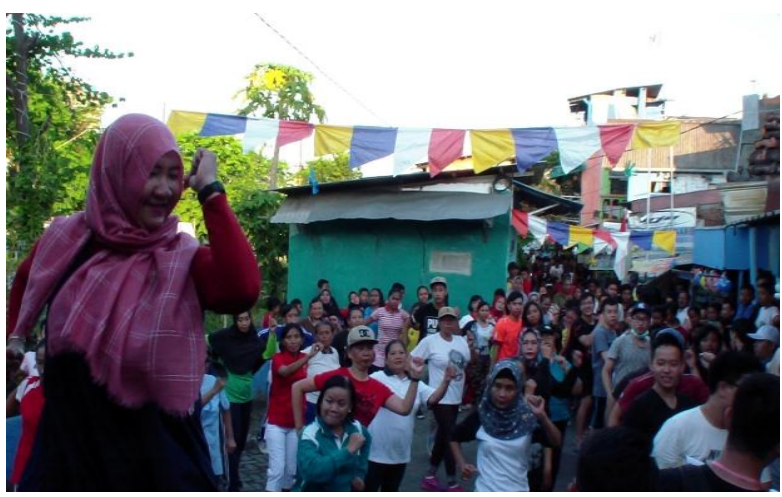

Gambar 3. Kegiatan Diawali Dengan Senam Bersama Warga, Pihak Terkait dan Mahasiswa

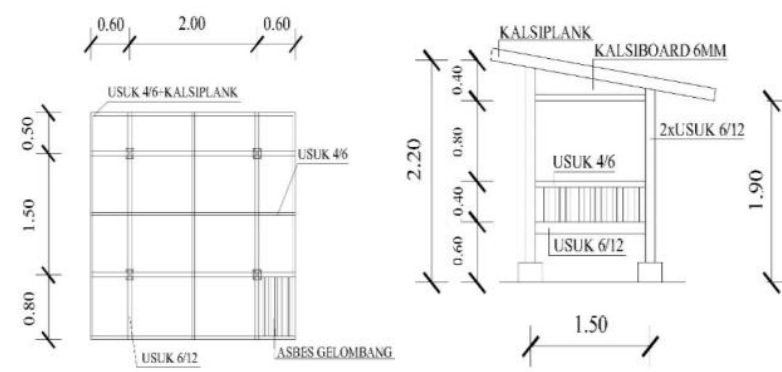

Gambar 4. Denah dan Tampak Samping Smoking Area 
Tabel 1. Kebutuhan Alat dan Bahan

\begin{tabular}{clcc}
\hline No & Alat/Bahan & Jumlah & Satuan \\
\hline 1 & Gergaji & 3 & buah \\
2 & Bor listtrik & 1 & buah \\
3 & Palu & 1 & Buah \\
4 & Pisau pahat & 2 & buah \\
5 & Gerinda & 1 & buah \\
6 & Kayu 6/12 & 10 & batang \\
7 & Kayu 5/7 & 2 & batang \\
8 & Kayu 4/6 & 14 & batang \\
9 & Papan 2/20 & 6 & batang \\
10 & Asbes gelombang & 4 & lembar \\
11 & Kalsiplank & 4 & batang \\
12 & Kalsiboard & 1 & batang \\
13 & Paku 5" & 1.5 & $\mathrm{~kg}$ \\
14 & Paku 4" & 1 & $\mathrm{~kg}$ \\
15 & Paku 3" & 1 & $\mathrm{~kg}$ \\
16 & Paku 2" & 1.5 & $\mathrm{~kg}$ \\
17 & Paku 1.5" & 0.5 & $\mathrm{~kg}$ \\
18 & Baut asbes & 1.5 & $\mathrm{~kg}$ \\
19 & Kuas 3" & 2 & buah \\
20 & Semen & 1 & $\mathrm{sak}$ \\
21 & Pasir & 1 & $\mathrm{sak}$ \\
\hline
\end{tabular}

Pembagian kelompok meliputi: kelompok persiapan, pemotongan kayu, pembuatan sambungan, pembuatan pondasi, pengukuran level, penempatan kerangka smoking area, pemasangan atap dan lantai, dan finishing. Proses persiapan meliputi pembersihan lokasi pembangunan smoking area dan persiapan alat dan bahan. Sementara lokasi dipersiapkan, tim pemotong kayu memotong dan menghaluskan kayu berdasarkan ukuran yang sesuai dengan desain yang telah dipersiapkan. Bagian-bagian kayu yang telah dipotong dibuat coakan-coakan dan lubang untuk mengakomodasi sistem sambungan kayu. Di lain sisi, tim pembuat pondasi mempersiapkan adukan mortar, menggunakan perbandingan standar antara pasirsemen-air, untuk membuat pondasi bata di empat titik yang akan digunakan untuk menyalurkan beban structural smoking area. Setelah masingmasing pondasi selesai dibuat, tim pengukuran level mengukur ketinggian relatif masing-masing pondasi agar posisi smoking area tidak miring. Di dalam pengukuran level digunakan alat sederhana berupa selang dan air. Setelah posisi pondasi benarbenar rata, maka kerangka smoking area yang telah disambung diangkat dan diletakkan pada pondasi dengan cara memposisikan masing-masing kolom struktur rangka smoking area pada titik-titik pondasi yang telah dipersiapkan. Setelah struktur rangka terpasang dengan baik, dilanjutkan dengan pemasangan lisplank dan lantai smoking area. Untuk memperindah tampilan smoking area yang telah dibuat, pada bagian akhir dilakukan finishing berupa pengecatan.

Tahap terakhir, paska pelaksanaan, berupa evaluasi kegiatan yang telah dilaksanakan. Pada tahap ini diadakan acara keakraban antara tim pengabdian dan masyarakat. Melalui acara tersebut tim pengabdi menyampaikan evaluasi mengenai pembangunan smoking area yang telah selesai dikerjakan, serta diskusi forum sebagai motivasi ekstrinsik bagi masyarakat setempat agar tumbuh kesadaran untuk hidup sehat-dalam kaitan dengan passive smoking.

\section{HASIL DAN PEMBAHASAN}

Gambar 5 menunjukkan lokasi yang dipilih untuk membangun smoking area. Lokasi yang dipilih sebagai tempat pembangunan smoking area ini berada di sebelah kiri gapura RT. Lokasi yang dipilih terletak di tengah-tengah antara RT 03 dan RT 04 sehingga membuat smoking area ini sangat strategis bagi masyarakat dalam penggunaannya.

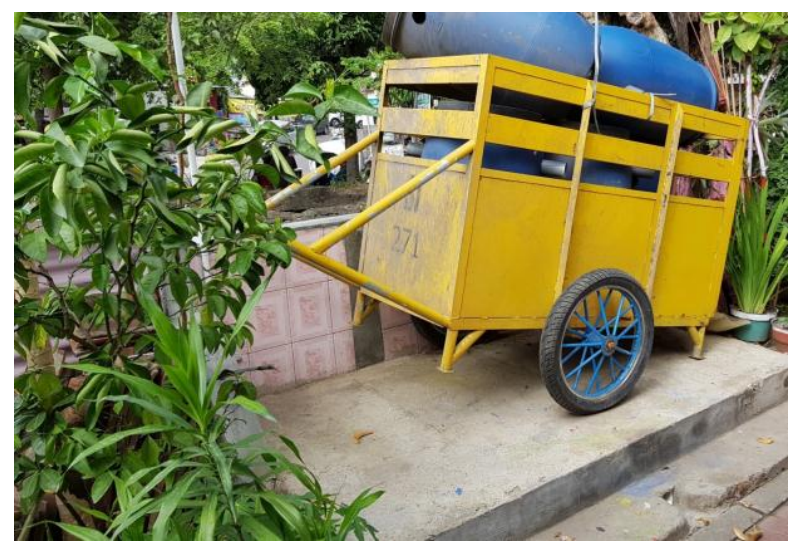

Gambar 5. Lokasi Pembangunan Smoking Area

Gambar 6 menunjukkan proses pemotongan kayu untuk membuat struktur rangka bangunan smoking area. Proses pemotongan dilakukan oleh kelompok mahasiswa yang beranggotakan masingmasing 3 orang. Proses pemotongan masing-masing bagian dari kayu dilakukan oleh kelompok yang berbeda-beda sesuai penugasan yang telah diberikan. Selain mahasiswa, dua orang tukang juga dilibatkan dalam pekerjaan ini. Mula-mula tukang mengerjakan satu bagian, kemudian dilanjutkan oleh mahasiswa. Dengan demikian, mahasiswa memperoleh gambaran secara nyata mengenai proses pengerjaan struktur kayu, sesuai dengan materi kuliah di dalam kelas.

Gambar 7 menunjukkan proses penghalusan permukaan kayu oleh mahasiswa peserta pengabdian kepada masyarakat berbasis service learning ini. Kayu-kayu yang telah dipotong oleh tim pemotong dilanjutkan ke proses selanjutnya, yaitu pengalusan permukaan kayu menggunakan gerinda. Tim penghalusan ini juga terdiri dari kelompok mahasiswa dengan anggota masing-masing tiga orang. Proses penghalusan ini diperlukan agar kayu yang dipasang sebagai rangka struktur smoking area terlihat lebih rapi, memiliki nilai estetika, serta 
tidak membahayakan bagi penggunanya. Pada gambar juga terlihat sekelompok mahasiswa bergantian mengerjakan penghalusan permukaan kayu. Di sini mahasiswa belajar bekerja sama di dalam kelompok dan berinteraksi dengan masyarakat untuk menyelesaikan pekerjaan yang telah direncanakan bersama untuk memberikan manfaat positif.

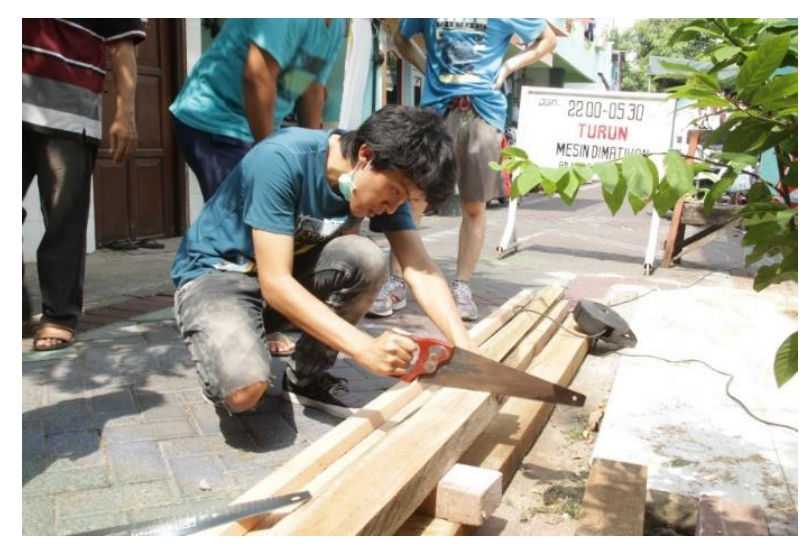

Gambar 6. Proses Pemotongan Kayu

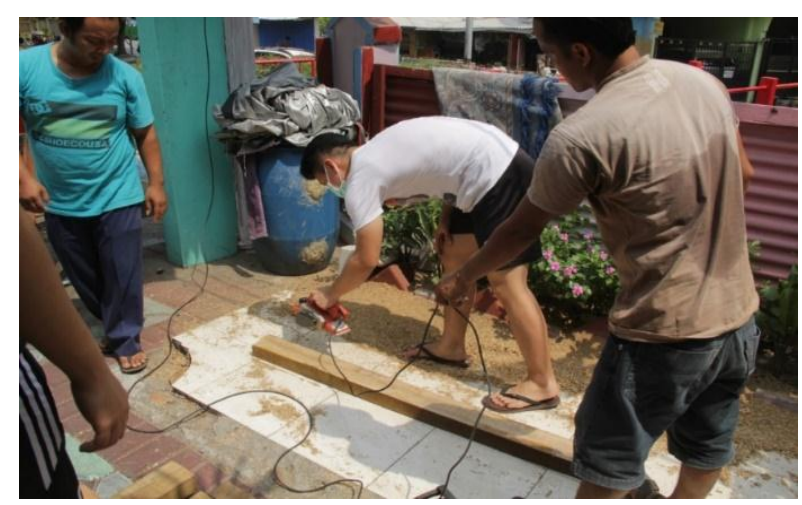

Gambar 7. Penghalusan Penghalusan Permukaan Kayu

Gambar 8 menunjukkan proses pembuatan coakan kayu, lubang-lubang, dan pasak sebagai kesatuan sistem sambungan kayu. Di dalam kelas, mahasiswa telah mendapatkan teori mengenai struktur kayu dan bagaimana mendesain kekuatan sambungan kayu. Berdasarkan ilmu yang telah didapatkan, mahasiswa yang tergabung ke dalam tim pengabdian ini telah mendesain kekuatan sambungan kayu pada bagian prapelaksaan kegiatan ini. Pada gambar terlihat mahasiswa sedang membuat coakan pada sambungan pen kayu menggunakan palu dan pisau pahat. Selain itu, pengaplikasian pengetahuan mengenai construction safety yang telah didapat juga diaplikasikan dengan penggunaan sarung tangan sebagai perlindungan telapak tangan ketika membuat coakan sambungan.

Bagian-bagian kayu yang telah selesai dipersiapkan kemudian dirangkai dan diletakkan di atas pondasi yang telah dibuat dan dicek terhadap kerataan (leveling). Setelah rangka smoking area terletak di atas pondasi, sambungan-sambungan kayu dieratkan. Sebagai pelengkap, pada bagian atap ditambahkan penutup atap dari asbes gelombang serta lisplank pada bagian perimeter smoking area. Setelah semua bagian rangka terpasang dengan baik, ditambahkan pelat kayu sebagai tempat duduk bagi pengguna. Hasil pembangunan smoking area diperlihatkan pada Gambar 9. Seperti yang dapat dilihat pada Gambar 10, seluruh kegiatan Service Learning diakhiri dengan acara ramah tamah bersama dengan warga dan pihak terkait.

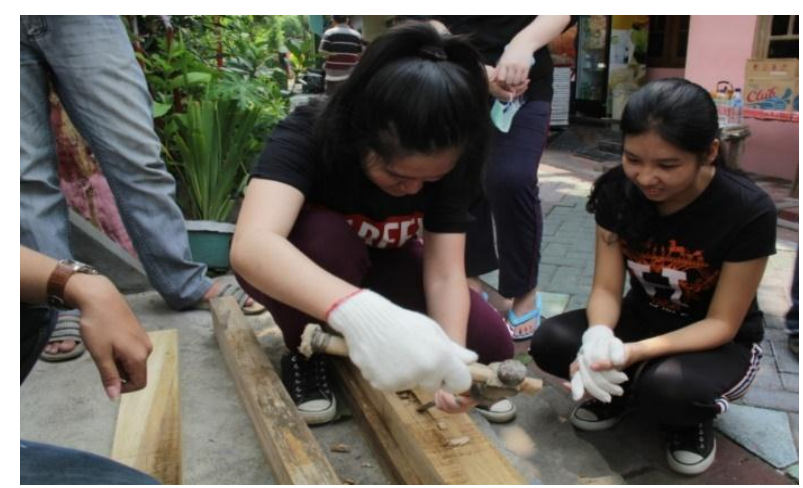

Gambar 8. Proses Pembuatan Coakan Sambungan Kayu

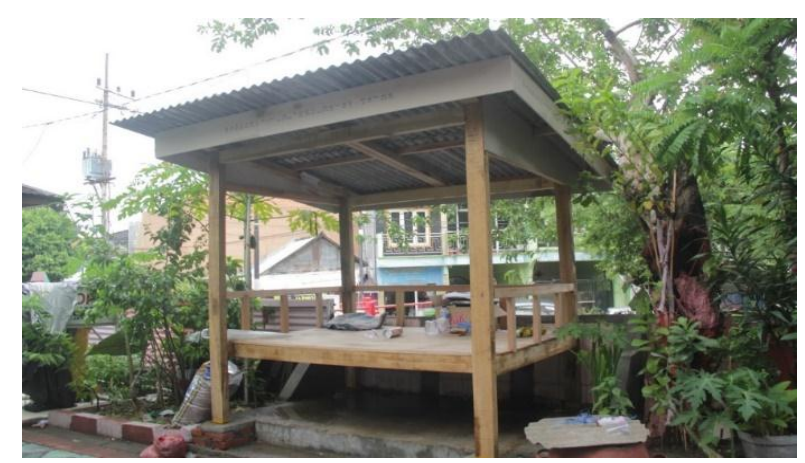

Gambar 9. Smoking Area Yang Sudah Selesai Dibangun

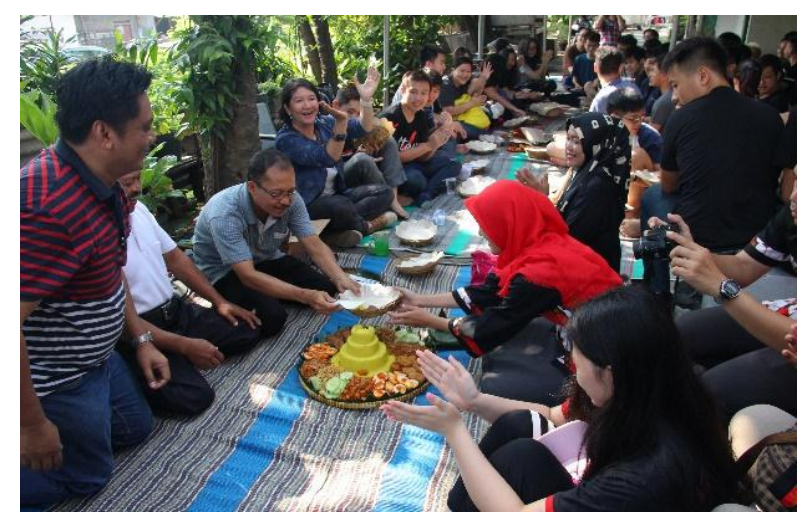

Gambar 10. Suasana Ramah Tamah Bersama Warga dan Instansi Terkait

Smoking area yang telah dibuat menjadi tempat berkumpul bagi masyarakat, baik dewasa, 
muda, maupun anak-anak, di Eks-Lokalisasi Dolly, RT 03/ RT 04 - RW 05, Kelurahan Putat Jaya, Jawa Timur. Melalui dibangunnya smoking area ini, orang-orang dewasa perokok aktif (ayah) tidak lagi merokok di dalam rumah atau pun di sembarang tempat sehingga mengurangi dampak perokok pasif, khususnya bagi kaum ibu dan anak-anak di wilayah tersebut. Selain itu smoking area ini juga digunakan sebagai tempat berkumpul pada malam hari untuk melakukan kegiatan positif, seperti membahas pengembangan RT, kegiatan RT, dan sebagai tempat mengaktualisasikan diri. Secara tidak langsung dengan dibangunnya smoking area ini, keamanan di daerah sekitar juga meningkat. Tidak berhenti sampai di situ, smoking area tersebut juga menjadi tempat belajar bersama bagi anak-anak sepulang sekolah. Tempatnya yang strategis dan nyaman, serta tambahan akses free Wi-Fi membuat suasana belajar menjadi lebih fresh dan menyenangkan.

Kegiatan SL ini diakhiri dengan acara ramah tamah bersama warga dan pihak terkait. Dimana terjadinya interaksi dari berbagai pihak.

\section{KESIMPULAN}

Sebuah smoking area telah dibangun di kawasan Eks-Lokalisasi Dolly, RT 03/ RT 04 - RW 05, Kelurahan Putat Jaya, Kota Surabaya, Jawa Timur, yang mengindikasikan tujuan pelaksanaan pengabdian masyarakat berbasis service learning di kawasan Eks-Lokalisasi Surabaya telah tercapai. Melalui dibangunnya smoking area ini kesadaran masyarakat akan bahaya perokok pasif meningkat, yang ditandai dengan berkurangnya jumlah perokok yang merokok di sembarang tempat maupun di dalam rumah. Selain itu smoking area yang dibangun juga bermanfaat bagi anak-anak untuk belajar sepulang sekolah. Manfaat berikutnya, yang secara tidak langsung timbul dari dibangunnya smoking area ini adalah meningkatnya keamanan di daerah sekitar.

Kegiatan pengabdian kepada masyarakat berbasis service learning ini juga melibatkan berbagai pihak yang turut berperan aktif dalam kegiatan positif untuk meningkatkan kualitas hidup sehat masyarakat di kawasan Eks-Lokalisasi Dolly Surabaya. Secara khusus bagi mahasiswa, kegiatan pengabdian kepada masyarakat berbasis service learning ini memberikan gambaran secara nyata mengenai kondisi masyarakat di sekitar mereka, dan bagaimana mereka bisa memposisikan diri untuk berinteraksi secara positif dan mengaplikasikan ilmu yang telah mereka dapatkan di dalam kelas.

Saran bagi keberlanjutan program pengabdian kepada masyarakat berbasis service learning adalah dengan mengembangkan atau memperluas daerah yang dilayani ke beberapa RT dan RW di sekitarnya. Dengan memperluas daerah yang dilayani maka dampak negatif perokok pasif dapat dikurangi sehingga kualitas hidup sehat masyarakat di kawasan Eks-Lokalisasi Dolly Surabaya meningkat.

\section{UCAPAN TERIMA KASIH}

Ucapan terima kasih tim pengabdi sampaikan kepada segenap pihak yang telah berpartisipasi secara aktif dalam menyukseskan pelaksanaan program pengabdian masyarakat berbasis service learning ini, meliputi:

1. Lembaga Penelitian dan Pengabdian Masyarakat UK Petra Surabaya

2. Program Studi Teknik Sipil UK Petra Surabaya

3. Lurah Kelurahan Putat Jaya Kecamatan Sawahan Surabaya

4. Puskesmas Putat Jaya

5. Departemen Sosial Kotamadya Surabaya

6. Departemen Kesehatan Propinsi Jawa Timur

7. Departemen Kesehatan Kotamadya Surabaya

8. Ketua RW 05 Kelurahan Putat Jaya, Ketua RT 03 RW 05 Kelurahan Putat Jaya, dan Ketua RT 04 RW 05 Kelurahan Putat Jaya

9. Warga RT 03 RW 05 Kelurahan Putat Jaya dan Warga RT 04 RW 05 Kelurahan Putat Jaya

10. Seluruh mahasiswa Program Studi Teknik Sipil UK Petra Surabaya peserta kegiatan Service Learning

\section{DAFTAR PUSTAKA}

Amelia, M. 2016. Perokok Pasif dan Resikonya. https://meetdoctor.com/article/perokok-pasifdan-risikonya. Diakses tanggal 27 Maret 2018.

Blackburn, C., Spencer, N., Bonas, S., Coe, C., Dolan, A. and Moy, R. 2003. Effect of Strategies to Reduce Exposure of Infants to Environmental Tobacco Smoke in the Home: Cross Sectional Survey. Bmj. 327(7409):257.

Britton, J. and Bogdanovica, I. 2013. Tobacco Control Efforts in Europe. The Lancet. 381(9877): 1588-1595.

Cahyani, R. and Rahmawati, D. 2016. Peningkatan Partisipasi Masyarakat Dalam Perbaikan Sanitasi Permukiman Kelurahan Putat Jaya Kota Surabaya. Jurnal Teknik ITS. 4(2):C144C149.

Callinan, J.E., Clarke, A., Doherty, K. and Kelleher, C. 2010. Legislative Smoking Bans for Reducing Secondhand Smoke Exposure, Smoking Prevalence and Tobacco Consumption. Cochrane Database Syst Rev. 4(4):CD005992.

Cancer Research, U. 2016. Passive Smoking. http://www.cancerresearchuk.org/aboutcancer/causes-of-cancer/smoking-and- 
cancer/passive-smoking. Diakses tanggal 26 Maret 2018.

Devina, E. 2017. Perokok Aktif vs Perokok Pasif. https://www.beastudiindonesia.net/perokokaktif-vs-perokok-pasiff. Diakses tanggal 26 Maret 2018.

Dunn, J., Greenbank, S., McDowell, M., Mahoney, C., Mazerolle, P., Occhipinti, S. and Steginga, S. 2008. Community Knowledge, Attitudes and Behaviors about Environmental Tobacco Smoke in Homes and Cars. Health Promotion Journal of Australia: Official Journal of Australian Association of Health Promotion Professionals. 19(2):113.

Eisner, M.D., Smith, A.K. and Blanc, P.D. 1998. Bartenders' Respiratory Health after Establishment of Smoke-Free Bars and Taverns. Jama. 280(22):1909-1914.
Evans, K.A., Sims, M., Judge, K. and Gilmore, A. 2011. Assessing the Knowledge of the Potential Harm to Others Caused By Second-Hand Smoke and Its Impact on Protective Behaviors At Home. Journal of Public Health. 34(2):183-194.

Fong, G.T., Craig, L.V., Guignard, R., Nagelhout, G.E., Tait, M.K., Driezen, P., Kennedy, R.D., et al. 2013. Evaluating The Effectiveness of France's Indoor Smoke-Free Law 1 Year and 5 Years after Implementation: Findings from the Itc France Survey. PLoS One. 8(6):e66692.

Hahn, E.J. 2010. Smokefree Legislation: A Review of Health and Economic Outcomes Research. American Journal of Preventive Medicine. 39(6):S66-S76.

Jarvis, M.J., Sims, M., Gilmore, A. and Mindell, J. 2011. Impact of Smoke-Free Legislation on Children's Exposure to Secondhand Smoke: Cotinine Data from the Health Survey for England. Tobacco Control. tc. 2010.041608. 